\title{
De Alcalá Galiano a Rodríguez Correa: la poesía subjetiva española entre dos prólogos (1834-1877)
}

\author{
Luis Caparrós Esperante \\ Universidade da Coruña
}

Habría que comenzar este trabajo con una declaración de intenciones. No parece apropiado o exacto hablar de literatura romántica española, con plena conciencia de tal, antes del primer cuarto del siglo XIX. ${ }^{1}$ Los debates desarrollados desde comienzos de siglo fueron de carácter fundamentalmente teórico y no llegaron a afectar a la sustancia de la escritura creativa contemporánea. Buena prueba de ello serían tanto el vacío literario que rodea las polémicas de Böhl de Faber como el sesgo de los textos de creación incluidos en la tan citada revista El Europeo (1823-1824), epítome de ese supuesto primer romanticismo. Aun si asumiéramos un criterio abierto y generoso para la caracterización y límites del movimiento, resultaría más romántico Meléndez -más auténtico como romántico- que cualquiera de los colaboradores de la revista. Es cierto que el revestimiento de muchos de aquellos textos respondía a cierta moda arqueológica, pero, por debajo de los sayones medievales al gusto de la época, se impulsaba el rescate de valores que, antes que románticos, eran reaccionarios desde el punto de vista estético y contrarios en pensamiento al nuevo orden laico y modernizador de la Ilustración. Y lo que es más importante, en esos textos no se abría paso una nueva sensibilidad marcada, para bien o para mal, por el sentido liberador de las Luces. Es la diferencia con el caso francés, donde, por poner un ejemplo, encontramos un conservador como Chateaubriand del que renegarían sus ásperos correligionarios españoles. Esto es especialmente cierto en el caso de la lírica, terreno en el que es visible la suplantación de los principios románticos más profundos, como la expresión conflictiva de la subjetividad, por los rasgos más superficiales del movimiento.

\footnotetext{
${ }^{1}$ El matiz de la "plena conciencia" me evita la confrontación con críticos como Sebold o Carnero y tampoco contradice los evidentes rasgos protorrománticos que podemos encontrar en Cadalso o Meléndez. Por citar una única referencia bibliográfica significativa, en cuanto estado de la cuestión, véase el resumen de posiciones de los dos primeros en sus colaboraciones para Historia de la Literatura Española, 8. Siglo XIX (I), dir. Víctor García de la Concha, coord. Guillermo Carnero (Madrid: Espasa-Calpe, 1997); especialmente en el apartado introductorio del propio coordinador, "El Romanticismo, entre dos siglos", XXXVIII-XLI, y en la bibliografía adjunta.
} 
En la débil e ineficaz expresión de la conciencia conflictiva del sujeto lírico está precisamente la clave de esa frustrante situación del romanticismo español. Sin embargo, esta conciencia conflictiva había apuntado a gran altura en los últimos líricos del XVIII español y, por paradójico que resulte, ahora parece eclipsarse o diluirse en un sentimentalismo retórico, generalizante, que desdibuja la expresión de lo individual. Lo anterior no significa que faltase reconocimiento del problema. Al contrario, y como se verá en el presente trabajo, tanto en el inicio real del movimiento en España como en su momento de disolución, cuando ni siquiera se define como romántico, se reconocen con suficiente lucidez tanto los retos como las insuficiencias.

El primer texto crítico que acerca la reflexión sobre la subjetividad a prácticas escriturales concretas -y además, líricas- es el prólogo de Alcalá Galiano a El moro expósito, de Saavedra, en 1834. Al margen de si cabe, o si no cabe, o hasta qué punto cabe hablar de romanticismo en el momento anterior, la evidencia es que ahora el movimiento tiene nombre propio y, lo que es más importante, creadores literarios bajo esa bandera. ${ }^{2}$ Alcalá Galiano, con buen criterio, no se remite tanto al ayer como al hoy. No echa mano de la arqueología, que llevaba a sus antecesores a definir como "romántico" el teatro áureo, sino que apela a la sensibilidad del hombre contemporáneo. Habla de literatura presente, de una corriente viva, actual, que conoce y analiza. ${ }^{3}$

El interés por la actualidad no evita que en este manifiesto romántico reencontremos, como no podía dejar de suceder, la relectura de los tópicos schlegelianos, rescatados mucho antes por Böhl de Faber, sobre la subjetividad consustancial al romanticismo alemán, asociada siempre al carácter nórdico:

Para buscar el origen de la escuela romántica de nuestros días, fuerza es que vayamos a Alemania. [...] Hoy es, y todavía los habitantes de los climas septentrionales, fríos y nebulosos, si bien aproximados a los del Mediodía por semejanza o identidad en su religión, leyes y estado social, todavía no pueden vivir ni expresarse como viven, sienten y se expresan los moradores de regiones cálidas, donde el sol es ardiente y despejada la atmósfera; porque los productos del sue-

${ }^{2}$ Véase, por ejemplo, la opinión de Caldera: "Forse solo Alcalá Galiano (dopo aver affermato che, se Rivas disobbedisce alle regole tradizionali, ne applica tuttavia altre) tenterà di formulare una nuova poetica" (Ermanno Caldera, Primi manifesti del romanticismo spagnolo [Pisa: Universitá, 1962], 69).

3 "Los cabezas y dogmatizadores de ambas parcialidades [clásicos y románticos] blasonan de origen más antiguo; pero aunque las composiciones de épocas menos recientes puedan ser clasificadas con arreglo a las nuevas doctrinas, todavía es cierto que los autores y críticos de los siglos pasados no conocieron estas divisiones, y que si entre ellos hubo escritores románticos, lo eran al modo del famoso monsieur Jourdain de Molière, que estuvo cuarenta años haciendo prosa sin saberlo" (Antonio Alcalá Galiano, "Prólogo" a Ángel de Saavedra, El moro expósito (París, 1834). Recogido en Navas-Ruiz, ed., El romanticismo español. Documentos (Salamanca: Anaya, 1971), 107-128 (p. 108). Todas las citas posteriores de este autor, en el texto principal o en las notas, van referidas a esta edición. 
lo, los usos y costumbres y las sensaciones e ideas tienen entre sí una correspondencia estrechísima y necesaria. (Alcalá Galiano: 109-110).

No está de más recordar, a este respecto, que Alcalá había sido años atrás uno de los contradictores del ideario romántico presentado por Böhl, cuando éste, desde posturas políticas y literarias bien diferentes a las del joven liberal, propagaba su versión de las nuevas ideas de los Schlegel. ${ }^{4}$ No habría de acabar aquí la evolución ideológica de Alcalá Galiano, paralela a la de tantos románticos liberales, muchos de ellos "exaltados", que habrían de desembocar en el conservadurismo o incluso en la negación, en mayor o menor grado, de sus antiguas creencias. ${ }^{5} \mathrm{Y}$ todo hay que decirlo, propiciando confusiones en la crítica sobre el significado político del conjunto de su obra y, en general, del romanticismo español. La foto final, convertida en foto oficial, vela cuidadosamente el sarampión radical que casi todos habían pasado durante los años de la revolución romántica, a la muerte de Fernando VII. ${ }^{6}$ Alcalá, entonces liberal exiliado en Inglaterra, como Saavedra, se había ido integrando con comodidad en el nuevo gusto gracias al eclecticismo natural de los británicos, lo cual no deja de señalar en el prólogo. ${ }^{7}$ De hecho, Alcalá Galiano demuestra conocer bastante mejor las literaturas francesa, italiana e inglesa que la alemana, de la que poco puede decir, aparte de estas notas casi patéticas: "De Alemania ya hemos dicho que es la cuna del Romanticismo. Lo que a nuestros ojos parecen rarezas de sus escritores, les es natural y está enlazado con sistemas filosóficos, llenos de misterio y oscuridad" (Alcalá Galiano: 121). Por eso resulta algo más concreto cuando proyecta esas misteriosas notas sobre las literaturas vivas que conoce mejor.

Para lo que aquí interesa, Alcalá Galiano acota una modalidad lírica que se ajusta a los rasgos más valorados en otros romanticismos: poesía construida desde un sujeto

\footnotetext{
${ }^{4}$ En el Cádiz de principios de siglo, Alcalá había fundado junto a José Joaquín de Mora, principal contradictor de Böhl, una Academia de Bellas Letras, de expresivo nombre. Bastante más tarde, ya en el exilio inglés, como el mismo Alcalá, el antes clasicista Mora sería autor de la primera traducción completa de una obra de Walter Scott. Véase Vicente Llorens, Liberales y románticos. Una emigración española en Inglaterra (1823-1834) (Madrid: Castalia, 1968).

${ }^{5}$ Para seguir la evolución de Alcalá Galiano, sigue siendo útil el estudio de Carlos García Barrón, La obra crítica y literaria de don Antonio Alcalá Galiano (Madrid: Gredos, 1970).

${ }^{6}$ Es el caso de Derek Flitter, cuya tesis acerca del carácter tradicionalista y conservador del romanticismo español descansa en gran medida sobre los textos teóricos previos al cambio político de 1833 y en la marginación, no sólo de Espronceda, sino de los primeros pasos de los autores románticos (Derek Flitter, Teoría y crítica del romanticismo español [Cambridge: Cambridge University Press, 1995]).

${ }^{7}$ Los británicos, escribe, tienen la poesía más rica entre las modernas "precisamente porque abandonando los autores reglas erróneas y no cuidándose de ser clásicos ni románticos, han venido a ser lo que eran los clásicos antiguos en sus días y lo que deben ser en todo tiempo los poetas" (Alcalá Galiano: 122).
} 
bien circunstanciado, poesía como indagación y expresión conflictiva de la subjetividad libre y, por ello, poesía que bascula sobre los dos polos del pensamiento y de la emoción. En otro lugar he recordado cómo la Estética de Hegel, tan importante en la constitución artística del XIX -y no sólo del romanticismo-, define precisamente la poesía lírica por su contenido subjetivo, frente a subgéneros más cercanos a la expresión diegética como la épica o el drama:

Para ésta [la lírica frente a la épica] el contenido es lo subjetivo, el mundo interno, el ánimo que considera y siente, que en lugar de avanzar hacia las acciones se detiene más bien ante sí como interioridad y puede por tanto también tomar como única forma y meta última la autoexpresión del sujeto. Aquí no existe pues ninguna totalidad sustancial que se desarrolle como un acontecer externo; sino que la intuición singular, el sentimiento y la consideración de la subjetividad en sí replegada comunica también lo más sustancial y lo más objetivo (Sachlichste) como lo suyo, como su pasión, estado de ánimo o reflexión y como producto presente de éstos. Esta plenitud y movimiento interno no puede entonces ser una expresión mecánica en su exposición externa, como es suficiente y tiene que exigirse en el recitado épico. Al contrario: el bardo debe manifestar las representaciones y consideraciones de la obra de arte lírica, como una realización subjetiva de sí mismo, como algo auténticamente sentido. ${ }^{8}$

Estaríamos, por tanto, ante una modalidad literaria de signo introspectivo y, por ello, cercana a la autobiografía o, por utilizar un término favorito de los románticos, a la “verdad”. Bien es cierto que Alcalá Galiano, no habla todavía de "poesía subjetiva”, sino de "poesía metafisica" -así, en cursiva-:

Búscanlo [objeto poético] asimismo en el examen de nuestras pasiones y conmociones internas: de aquí la poesía metafísica, tan hermosa en el mismo lord Byron, en varios alemanes, en los ingleses Coleridge y Wordsworth y en los franceses Víctor Hugo y Lamartine (Alcalá Galiano: 124).

En estas palabras, que ya no remiten a Calderón o a las gestas medievales, como venía siendo habitual entre los comentaristas españoles, se destaca la conciencia que tiene el prologuista de la importancia de la subjetividad como principal clave definitoria de la nueva sensibilidad lírica. Aunque se refiera a una concreta modalidad entre el variado repertorio de temas y actitudes de la literatura contemporánea, conviene subrayar que ya antes, cuando habla en un plano más general, ha establecido "la regla de que sólo es poético y bueno lo que declaran los hechos de la fantasía y las emociones del ánimo" (Alcalá Galiano: 110). Como bien señala Susan Kirkpatrick, "la realidad del sujeto individual es la prueba definitiva de la verdad de la poesía".

8 Georg W. F. Hegel, Estética, trad. Alfredo Llanos, 8 vols. (Buenos Aires: Siglo Veinte, 1985), VIII, 109. Para una valoración más detallada del pensamiento de Hegel en relación a esta materia, véase mi trabajo "La construcción de la subjetividad lírica desde los itinerarios inversos de Blanco White y de Böhl de Faber" (Bulletin Hispanique. 110.2 [2008], 487-511).

${ }^{9}$ Susan Kirkpatrick, Las románticas. Escritoras y subjetividad en España, 1835-1850 (Madrid: Cátedra, Universidad de Valencia e Instituto de la Mujer, 1991), 55. 
Sin embargo, El moro expósito no se ajusta a la definición que él mismo hace de "poesía metafísica” y, por lo mismo, le convienen mucho mejor otras notas que el prologuista señala, como su medievalismo. Bien es cierto que la crítica está advertida de que, en realidad, Alcalá Galiano habla más del romanticismo en general que del libro concreto que prologa. Aun así, casi añadiría que esas otras notas refuerzan la lógica interna de su teoría sobre lo romántico, por el hecho de ser Ángel de Saavedra meridional y no septentrional, es decir, con el déficit consiguiente de subjetivismo derivado del esquema schlegeliano. En cualquier caso, y aunque el poema prologado lo desmienta, ya tenemos aquí el diseño de una tendencia concreta, la de la "poesía metafísica" o subjetiva, que busca y buscará un difícil acomodo en la literatura española, si bien Alcalá no acaba de delimitar su significado.

El duque de Rivas no podía ser un buen modelo para este tipo de poesía y aún lo sería menos a medida que su obra fue creciendo. A diferencia de él, Espronceda sí cumpliría ese papel de poeta "metafísico", según la opinión generalizada entre sus contemporáneos. En el prólogo de Antonio Ros de Olano a El diablo mundo, en 1841, ya se encuentra una caracterización de la poesía subjetiva ajustada al poema analizado, aunque en ningún momento llegue Ros a utilizar la expresión. En cualquier caso, la nueva poesía se define ahí como de reflexión, de examen, pero sin olvidar nunca el corazón:

La sociedad se encuentra ya en edad de madurez; nuestra época es la de reflexión y examen, como las de Homero y Dante fuéronlo de entusiasmo y fuerza; pero que el corazón manda el mundo es una máxima irrefutable: con él han dominado los héroes, y con él los filósofos ardientes que lograron imprimir su sello en la humanidad, propagaron sus respectivas doctrinas. ${ }^{10}$

Los matices de Ros de Olano completan la caracterización dada antes por Alcalá Galiano, pues suma los dos polos definitorios: el de la reflexión, lo filosófico, y el del sentimiento. Claro que la irrupción de la poesía "subjetiva" de Espronceda es posterior al prólogo de Alcalá. Pero si él es reconocido como el primer poeta subjetivo del XIX español -moderno y actual, por tanto-, habremos de dar un salto en el tiempo hasta Bécquer para lograr ejemplificar la categoría, de un modo palpable, en el momento, ciertamente tardío, en que ésta comienza a afianzarse en el pensamiento poético del XIX español.

10 Antonio Ros de Olano, Antonio, “El diablo mundo. Poema de don José de Espronceda”, en José de Espronceda, El estudiante de Salamanca. El diablo mundo, ed. Robert Marrast (Madrid: Castalia, 1982), 159-168 (p. 164). 
La leyenda becqueriana, forjada por su amigo Ramón Rodríguez Correa en el prólogo a su obra póstuma, en 1871, sobrescribía en los poemas un argumento de dolor y frustración amorosa que parecía servir bien a la construcción de la imagen subjetiva de Bécquer. La ordenación misma de los poemas, ajena al poeta y arreglada por los editores según un forzado esquema narrativo, pretendía realizar o realzar la intención anunciada en el prólogo. En realidad, la poesía de Bécquer no necesitaba de tales arreglos falsamente biográficos para aparecer en sí misma, desnuda, como un espacio de autorreflexividad donde se revelaba una voz, un sujeto lírico singular y reconocible. ${ }^{11}$

Prestemos atención a los matices, pues es en la voz, con independencia del ciudadano que la escribe o la describe, donde está la clave esencial del proceso de maduración de la conciencia del sujeto lírico. De Espronceda a Bécquer hay una evidente fijación de esa conciencia, que siempre marcha paralela a la tensión entre la mano que escribe y la voz que habla en el poema. Llegados a Bécquer, esto último es lo que adquiere valor propio en el texto, por encima de la posible autenticidad de aquello que se poetiza o de la correspondencia entre quien habla y quien escribe. Es más, la poesía de Bécquer es particularmente elusiva a este respecto, pese a las apariencias, pese a que la convención biografista, como conviene repetir, fuese parte importante de la estrategia discursiva heredada del romanticismo. De hecho, la Teresa esproncediana quiere aparecer deliberadamente como aquella Teresa real, de apellido Mancha, que todos debían de conocer en Madrid, y en ningún momento el poeta la disfraza de pastorcica bucólica. Por otra parte, ahí, en su circunstanciación, reside en gran medida su efectividad lírica. La estrategia creativa de Bécquer, la construcción de su sujeto lírico, ya no necesita de esas herramientas para hacerlo creíble y sentimentalmente eficaz. Aplicado al caso de Bécquer, el prólogo de Rodríguez Correa podría haber prescindido perfectamente del efecto biográfico, a esas alturas muy desgastado, pues el amigo metido a prologuista demuestra ser capaz de destacar, con igual o mayor relevancia, la vinculación del poeta con los valores de la llamada "poesía subjetiva". Correa, en fin, sabe que esta modalidad vendría a ser, según sus palabras, un rasgo decisivo de modernidad. Éste es, sin duda,

\footnotetext{
${ }^{11}$ Remito al lector, para este aspecto crucial de la recepción becqueriana, a los trabajos de Rafael Montesinos, especialmente su Bécquer. Biografia e imagen (Barcelona: RM, 1977), y de Robert Pageard, Bécquer. Leyenda y realidad (Madrid: Espasa-Calpe, 1990). También, como ampliación de estas ideas, pueden consultarse mi artículo: "Bécquer. Estética del borrador", Bulletin Hispanique, 99 (1997), 437-455, o la introducción a la edición electrónica de las Rimas, en el Centro Virtual Cervantes: Luis Caparrós, ed., Gustavo Adolfo Bécquer, Rimas. URL:< http://cvc.cervantes.es/obref/rimas/> (Consultado el 8 de mayo de 2009.)
} 
uno de sus aciertos como prologuista y aún lo repetirá en el prefacio de la segunda edición de las Obras, en 1877.

El concepto de poesía subjetiva, heredero de la poesía metafísica de Alcalá Galiano, va a ser de hecho un rasgo discriminador de uso corriente en el pensamiento poético de último cuarto del XIX, si bien con retraso evidente. Pero el carácter elusivo del sujeto lírico becqueriano, a diferencia del de Espronceda, y las afinidades literarias declaradas del propio poeta no se lo ponían fácil a Correa. ¿Cómo conjugar esa modernidad alegada en el prólogo con sus reivindicaciones clasicistas? ¿Acaso el clasicismo no era la negación misma del subjetivismo? Pero en la materialidad de los poemas, ¿no era cierto que la desnudez becqueriana realzaba la expresión más cruda del yo? La vinculación del poeta con la tradición clasicista sevillana, razonaba Correa, sería una rémora que solamente gracias a su genio lograría superar: "él no dejaba ver su lacerado espíritu, sino envuelto entre las elegantes formas de plasticismo sevillano, pura y rígida escuela a que sólo ha faltado ser más subjetiva y franca para ser perfecta" (Correa 1871: xxi). ${ }^{12}$ La subjetividad, como se advierte, va ligada, según corresponde, a la franqueza, incluso a la espontaneidad, al hombre real. La llamada "poesía subjetiva" haría depender la belleza de un orden vivencial y hasta moral superior a la belleza misma, pues ése es

el camino de lo bello (en cualquier sentimiento fingido no hay belleza), a cuyo término está la única moral, la moral subjetiva por decirlo así, la que se desprende de todas las sensaciones que han agitado una vida. Todo hombre que siente, esto es, que puede conmoverse profundamente, está en vías de perfeccionarse y de llegar a la verdadera moral; la moral, que a mi juicio es la vida de la idea, la vida del cuerpo y del alma que viven en paz y armonía. (Correa 1871: XXIII).

Para Rodríguez Correa la importancia de la poesía subjetiva en el renacer lírico español del XIX, y concretamente en Bécquer, reside precisamente en su rareza dentro de la tradición propia. “¿Por qué esta poesía subjetiva ha brillado tan poco en España, y cuando tal ha sucedido se ha verificado dentro de una excepción del sentimiento humano?" (Correa 1871: XXVI). Alcanzamos aquí un punto crucial para entender las dificultades de este tipo de poesía en España. La explicación de Correa nos va a desviar de lo puramente literario hacia el marco ideológico del progresismo liberal del siglo. No se trataría de una carencia racial, por parafrasear los términos del prólogo, sino la con-

\footnotetext{
${ }^{12}$ Ramón Rodríguez Correa, "Gustavo Adolfo Bécquer”, en Obras de G. A. Bécquer (Madrid: Imprenta de T. Fortanet, 1871), VII-XXXV. Todas las referencias posteriores a este texto del autor, en el cuerpo del artículo o en nota, remiten a esta edición, de la que existe versión en línea: Rimas, ed. de Luis Caparós Esperante. [Alcalá de Henares]: Instituto Cervantes (Centro Virtual Cervantes). URL:

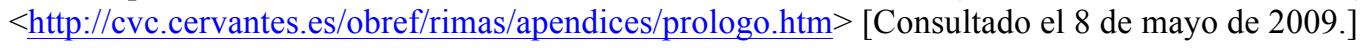


secuencia obligada de la rigidez política $y$, especialmente, de la rigidez religiosa del desarrollo histórico español:

La poesía subjetiva no había brotado aún, porque no era tiempo, pues ocupados los poetas en ensalzar sus héroes, en adorar sus santos, aliados fieles en guerras contra agarenos, y en reconquistar para la religión y la patria antiguas el terreno arrebatado, no habían abandonado todavía el campo de batalla, la plática en la asediada tienda de combate, ni el rezo a favor de la victoria entre las arcadas del templo, para sustituir el mundo exterior, que les embargaba, con la contemplación de sí mismos, al contacto de una sociedad tranquila y adecuada a la reflexión y al examen (Correa 1871: XXVI).

Rodríguez Correa nos da, por tanto, una explicación netamente ideológica de la insuficiente modernidad del romanticismo español y de sus derivados. La poesía subjetiva es, según él la define, un fruto liberal, unido por sólidos lazos a la expresión del pensamiento libre. Ello no significa necesariamente que la religión fuese obstáculo por sí misma. Según señala, escritores y poetas naturalmente subjetivos habrían sido Santa Teresa, fray Luis de León, San Juan de la Cruz, Juan de Ávila, fray Luis de Granada, pero todos ellos, "a pesar de haber sido después canonizados, tuvieron que humillar sus puras frentes y anublar sus radiantes inteligencias ante las negras sotanas de los inquisidores" (XXVIII). El escritor subjetivo, poseedor entonces de "un espíritu peligroso", de "este enemigo interno",

suprimió su personalidad en todas las concepciones de su inteligencia, y semejante a tímidas aves que vuelan rastreando o se pierden tras las nubes, la hipocresía de la forma ocultó los sentimientos, o el misticismo fue el espacio a que se remontó sereno el espíritu, sin que por ello lograra escapar a persecuciones inesperadas (Correa 1871: XXVIII).

La literatura del período barroco vendría a ser así un exacerbamiento de la forma -“hipocresía de la forma”, escribe literalmente-, victoria del oropel, del estilo en suma, y todo ello para recubrir del modo más conveniente el silencio clamoroso de la intimidad. Correa no hace sino retomar un punto candente en el enfrentamiento inicial entre conservadores y progresistas del siglo XIX, muy visible en el caso inaugural de Blanco White. La poesía subjetiva se confunde, en este contexto, con el término usado por Alcalá Galiano, aquel de poesía metafísica. La relación entre ambas expresiones es ilustrativa de los contornos entre los que se mueve el concepto. La poesía subjetiva sería metafísica o filosófica en un sentido muy próximo al que este último adjetivo tenía en el XVIII: como expresión del pensamiento, pero de un pensamiento libre, sin excesivas trabas ideológicas, morales o religiosas. El uso alternativo del adjetivo subjetiva, que no contradice lo anterior, reforzaría la componente introspectiva, franca y singularizada, en que se produce esa meditación sin trabas. 
Retomamos así, a partir de Correa, un aspecto, digamos político, que no casa en apariencia con nuestra percepción habitual de la poesía becqueriana. El libre ejercicio de la subjetividad resulta ser un desafío al poder, cuyos tentáculos no se agotan en el plano más visible, sino que, de modo mucho más hondo y eficaz, afectan a lo que Foucalt ha denominado "el régimen político, económico e institucional de producción de verdad". ${ }^{13}$ Es cierto que el ciudadano Bécquer era o parecía conservador, pero no es menos cierto que sus amigos liberales, Correa incluido, ejercieron la censura contra algunas rimas que resultaban especialmente incómodas sobre papel impreso. Sin duda, la apuesta becqueriana por mostrar el corazón y aun el cuerpo al desnudo, de modo radical y conflictivo, encajaba mal aun para el orden liberal.

Permitámonos una nueva mirada atrás. También Alcalá Galiano, en el prólogo antes citado de 1834, había asociado la inanidad ideológica del XVII a las formas despóticas del poder:

Y quien leyere con atención crítica y filosófica la historia de España durante el siglo XVII y viere qué estudios se permitían entre nosotros, qué estímulos excitaban los ingenios y qué ideas andaban dominantes, encontrará allí la explicación de la barbarie en que vino a caer la nación española bajo los príncipes austriacos. Con lo cual, y con estudiar el carácter nacional, habrá entendido la esencia y causa del culteranismo; porque éste consiste en la hinchazón y sutileza de conceptos, y por lo mismo es defecto natural de una gente, de suyo ingeniosa y dotada de viva fantasía, a la que estaba vedado adquirir ideas nuevas y hasta dedicarse a sólidas meditaciones; a quien el poder crecido de sus reyes daba vanidad, mas no felicidad y verdadera grandeza, y para la cual no eran el gobierno, las leyes y la religión materia de examen libre y de atrevida controversia, sino objetos de resignación violenta, de obediencia precisa y de resignación medrosa. En tal estado, forzoso era que se entretuviese en refinar pensamientos triviales y en abultar ideas comunes, malgastando (como dijo un crítico de nuestros días al hablar de uno de nuestros mejores poetas de aquella época) sus grandes fuerzas naturales en juegos y saltos de volatines (Alcalá Galiano: 115).

Alcalá Galiano -más cerca aquí de Quintana que de Blanco White- daba así la vuelta a los argumentos utilizados por Agustín Durán en 1828 para defender su concepción historicista y conservadora del romanticismo. Escribía entonces Durán:

Después de él [de Fernando el Católico], Carlos V y Felipe II completaron la obra y, sujetando el uno a Padilla y el otro a Lanuza, ahogaron casi enteramente las formas representativas y consolidaron la monarquía absoluta. Desde tal momento, el español, privado de toda discusión política y religiosa, se vio libre del germen de las discordias y conserva aún la opinión monárquica y cristiana que le distinguía en los siglos XVI y XVII. [...] Estamos los españoles con la imaginación muy cercanos a la conquista de Granada, para haber olvidado los nobles recuerdos de los caballeros árabes y los cristianos que, peleando en el campo de honor, se disputaban el premio en generosidad, cortesía y amores. ¿Y por qué no ha de ser así? [...] Por mi Dios, por mi rey y por mi dama es aún la divisa del noble castellano, y sobre ella han girado todas las creaciones poéticas donde brilla el genio nacional, desde principios a fines del siglo XVII. ${ }^{14}$

\footnotetext{
${ }^{13}$ Michel Foucault, Un diálogo sobre el poder y otras conversaciones (Madrid: Alianza Editorial, 2001), 156.

${ }^{14}$ Agustín Durán, Discurso sobre el influjo que ha tenido la crítica moderna en la decadencia del teatro
} 
Como en Durán, no faltará en nuestro pasado reciente quien alabe las virtudes de la censura, de la privación de toda discusión política y religiosa, para excitar la creación literaria. Con Alcalá Galiano y con Correa, en los extremos del arco temporal elegido, nos movemos en otro orden de ideas. Y en el contexto de este trabajo, no resultará ocioso recordar que ideas semejantes a las de Alcalá o Correa habrán de resonar en el desdén de futuros poetas republicanos, como Antonio Machado y Luis Cernuda, hacia buena parte de la literatura del XVII, volcada según ellos en la adoración de la imagen y del ritmo en detrimento del pensamiento. Estas ideas repuntarán incluso en la saturación gongorina del año veintisiete, preámbulo del vuelco existencial del surrealismo. Y si nos acercamos un poco más a la hora actual, observaremos la frecuencia con que críticas semejantes -abiertas o veladas- serán de aplicación a escritores como Umbral, supuesto continuador de la tradición castiza del "gran estilo" y del ingenio.

Regresemos al prólogo de Correa, para quien el romanticismo español -ligado al naciente Estado liberal- habría sido una oportunidad inmejorable para dar plena expresión a esa intimidad, tanto por su confeso subjetivismo idealista como por la existencia de condiciones políticas de libertad. A pesar de ello, viene a sugerir Correa con lógicas cautelas, el peso excesivo de la tradición literaria española dejó muy poco espacio para esa liberación artística e ideológica, tal como lo demostraría la deriva de los románticos hacia valores historicistas y conservadores o, simplemente, reaccionarios en lo estético:

Mientras Zorrilla nos refiere imperecederas tradiciones, Espronceda nos habla de sí mismo y del alma humana, y con él esa poesía subjetiva, producto de la libertad del pensamiento, toma carácter de naturaleza entre nosotros, demasiado apegados aún a la admiración de tiempos que pasaron, hasta el punto de que hombres casi demagogos son perfectos reaccionarios en cuanto hablan en verso (Correa 1871: XXX).

Vale la pena hacer un alto en esta última afirmación, pues apunta a la singularidad de Bécquer en el contexto de las transformaciones líricas del XIX español. Es cierto, como vimos, que se movía en círculos de pensamiento conservador -y no entraré a discutir cómo este hecho contrasta con las ideas de sus amigos más próximos o las de su propio hermano-- Es cierto, igualmente, que sus devociones literarias expresas fueron para el neoclásico Alberto Lista o para Fernando de Herrera, a quien aquel tanto admiraba. Sin embargo, como Correa entiende perfectamente, cualquier renovación en los modelos líricos debe darse de modo simultáneo en el plano de la expresión y en el de to peculiar (Madrid: Imprenta de Ortega y Compañía, 1828). En Navas-Ruiz, ed., 1971, 54-100 (p. 95). Para la figura de Durán y para el análisis de sus ideas, es imprescindible el trabajo de David T. Gies, Agustín Durán, A Biography and Literary Appreciation (Londres: Tamesis Books, 1975). 
los contenidos. La valentía moral de Bécquer, que provocaría la censura de las Rimas e incluso la incomprensión clerical en su Sevilla natal, se acompaña de una apuesta francamente innovadora en el terreno de las formas, mucho más libres y arriesgadas de lo que era convención en el momento. El prologuista, como curándose en salud, no deja de señalarlo en el prefacio de 1877 , con cierto embarazo. ${ }^{15}$ Precisamente, aquella "hipocresía de la forma", que él mismo señalaba en la literatura áurea, representaría lo contrario de la desnudez becqueriana: servía para suprimir u ocultar la personalidad, la expresión sincera y el libre análisis de las emociones que desarrollará Bécquer en sus poemas. Dicho de otro modo, "como todos los autores de estima, es Gustavo revolucionario, es decir, innovador y creador, amante de la verdad" (Correa 1871: XXII).

Rodríguez Correa concluye esta revisión de la poesía subjetiva con un par de matices interesantes para nuestra perspectiva: "Creo haber probado lo bastante que, lejos de ser la poesía esencialmente subjetiva imitación de extranjeros líricos, es resultado natural de la moderna civilización, por lo cual comienza hoy a nacer en España, más atrasada en todo que otros países" (Correa 1871: XXXI). Es decir, la poesía "esencialmente subjetiva" es un rasgo de modernidad lírica que no supone un alejamiento de la propia tradición, como se habría querido ver, sino el desarrollo de una potencialidad frustrada. Además, la poesía subjetiva es "producto de la libertad del pensamiento". Al margen, ésta es una idea que, no sé si de modo sorprendente, habremos de encontrar también en un conservador de bulto como Menéndez Pelayo, junto a una honesta apreciación de la modernidad de Espronceda:

De aquí que el romanticismo que algunos llaman subjetivo y otros impropiamente fisiológico, cuyo más alto representante entre nosotros es Espronceda, difiera profundamente del romanticismo histórico o legendario del Duque de Rivas y de Zorrilla, inspirado a medias en Walter Scott y en los romances. La poesía de Espronceda tiene un carácter más moderno y más francamente revolucionario, así en la esfera de las ideas como en la de las formas. ${ }^{16}$

\footnotetext{
${ }^{15}$ De una parte, Correa señala que "como galanura de forma, pureza de dicción y corrección de estilo hay muchos que le aventajen, y éstos son los que deben imitarse siempre". De la otra, añade: "Pero lo imposible de imitar en Bécquer es su propio espíritu, su manera de ver, como dicen los pintores, su idiosincracia, como lo llaman los naturalistas" (Correa 1877: IX). La consideración de Bécquer como poeta descuidado en la forma sería habitual en los años posteriores, incluso entre sus defensores. Como en el caso anterior, todas las citas de Correa que corresponden a esta segunda edición, en el cuerpo del artículo o en las notas, siguen el texto publicado en: Rodríguez Correa, Ramón, "Al lector", en Obras de G. A. Bécquer, I, segunda ed., Madrid: Fernando Fe, 1877, pp. V-XI. Existe versión en línea: Rimas, ed. Luis Caparrós Esperante. [Alcalá de Henares]: Instituto Cervantes (Centro Virtual Cervantes). URL: $<$ http://cvc.cervantes.es/obref/rimas/apendices/prologo01.htm $>$ [Consultado el 8 de mayo de 2009.]

${ }^{16}$ Marcelino Menéndez Pelayo, Estudios y discursos de crítica histórica y literaria, VII (Madrid: CSIC, 1942), 274.
} 
La inteligencia de don Marcelino pone el dedo en la llaga, y no sólo por distinguir la subjetividad lírica, necesariamente reflexiva, de lo meramente emocional o "fisiológico". Espronceda, en razón de su subjetivismo, tiene "un carácter más moderno". Y, además, su sentido revolucionario no se queda sólo en el plano de las ideas, pues las nuevas ideas, cuando lo son de verdad, se corresponden siempre con nuevas formas.

Cinco años más tarde, en 1876, habría de volver Rodríguez Correa sobre las mismas reflexiones. En la primera mitad de octubre de ese año se desarrolló en el Ateneo madrileño un debate sobre el "estado actual de la poesía lírica", con la participación de Núñez de Arce junto a críticos como Revilla, Vidart, Valera o Canalejas, de un modo u otro ligados a ideas progresistas o al krausismo. La altura general de la discusión fue bastante pobre, si atendemos a las reseñas publicadas a lo largo de varios números de la Revista Europea.$^{17}$ La confrontación más animosa se dio en torno a la relevancia de la forma frente a la idea. A pesar de las atinadas correcciones de Valera o Canalejas, el resobado dilema del líquido y la botella resultó una metáfora útil para la toma de partido. Tirando de ese hilo, buena parte de los polemistas defendieron la primacía del contenido filosófico o del histórico, sin demasiados matices, frente a quienes, como Juan Valera, entendían que lo esencial lírico reside en la pura belleza, la que solamente logra expresarse mediante la forma.

En el debate, Rodríguez Correa identificaría una vez más la llamada poesía subjetiva con la escuela romántica. Frente a ella, estaría la escuela clásica "u objetiva". La postura de Correa, tan diplomático como el mismo Valera, expresa voluntad de superación de ambas, pues tan criticable le parece el abuso contenidista de la primera como la rigidez formalista de la segunda. ${ }^{18}$ Dentro de ese contexto, y aunque el debate parecía

17 "Estado actual de la poesía lírica en España", Revista Europea, 143 (19 de noviembre de 1876), 671672 ; 144 (26 de noviembre de 1876), 703-704; 145 (3 de diciembre de 1876), 735-736; 147 (17 de diciembre de 1876), 146-148; 148 (24 de diciembre de 1876), 801-810. La revista está ahora digitalizada y puede consultarse en línea: Ateneo de Madrid. Biblioteca Digital. URL: $<$ http://www.ateneodemadrid.net/biblioteca_digital/RevistaEuropea.htm $>$ [Consultado el 8 de mayo de 2009.]

${ }^{18}$ Interviene Correa, con buen tino y sin dejar de recordar aquella "hipocresía de la forma" que había denunciado ya en 1871: "Para el orador, la poesía lírica es subjetiva, siendo el poeta el vaso delicado donde se encierra la esencia de lo subjetivo. La forma y el fondo no son antagónicos, como por algunos se pretende. En España sobre todo, no es posible tener dos ideas sin ponerlas inmediatamente la una enfrente de la otra. La escuela clásica u objetiva (que se cuida principalmente de la forma), y la romántica o subjetiva (que atiende con mayor esmero al fondo), han reñido batalla entre nosotros desde el tiempo de las famosas escuelas sevillana y castellana. Realmente en España ha existido siempre el vicio de la forma. Todos saben las ridiculeces en que han incurrido los poetas gongoristas. Estos predominios del fondo o de la forma son siempre viciosos. Sin fondo no es posible que haya forma, y viceversa, pues ambos elementos están tan compenetrados, que es totalmente imposible abstraerlos. Creo al mismo tiempo que debe 
resucitar el viejo contencioso entre clásicos y románticos -un modo de echar balones fuera-, el tono excesivamente generalizador no dejaba de apuntar a cuestiones más inmediatas. ¿Era Bécquer más subjetivo por extremar el sentimentalismo hasta el amaneramiento? ¿Eran más objetivos Campoamor o Núñez de Arce por privilegiar el sentido trascendente -filosófico, docente, histórico- de la lírica? ¿Hasta qué punto la subjetividad estaba reñida con el sentido trascendente que, para casi todos, debía reclamar la lírica?

En el debate, observaremos que detrás de cada una de las etiquetas formuladas se amparaban las prácticas de los tres poetas que, con amplio consenso, ejemplificaban las grandes tendencias del momento: Núñez de Arce, Campoamor y Bécquer. A riesgo de simplificar demasiado, en ellos podían verse representadas la corriente histórica, la filosófica y la intimista. ${ }^{19}$ Aun así, Francisco de Paula Canalejas, en su papel de reseñador y moderador, procuró concertar las opiniones divergentes en torno a la idea de la esencial subjetividad de la lírica:

que la poesía lírica es esencialmente subjetiva; que su anhelo se cifra en rodear de luz, en descubrir ese hombre interior que palpita en el fondo de nuestra conciencia y que va como emparedado y exánime bajo el peso de los sentidos, de las preocupaciones y de los afanes de la existencia histórica. ${ }^{20}$

Parece claro que nadie, a estas alturas, se atrevía a negar ese carácter. La poesía subjetiva parecía haber alcanzado el suficiente prestigio, entrados en el último cuarto del siglo XIX, como para ser componente indiscutible de todo gran poeta, al margen de otras caracterizaciones posibles. Mas a pesar de este afán de conciliación del moderador, quedaba claro que el "hombre interior", que desde nuestra perspectiva representaba casi exclusivamente Bécquer, interesaba mucho menos a la mayoría de los polemistas que la "existencia histórica". Podría incluso entenderse, por debajo de las palabras conciliadoras, que ambos polos eran incompatibles. Habida cuenta del predominio de voces del progresismo liberal en la discusión, ¿dónde quedaba la antigua conciliación del yo

existir completa libertad en la forma, y que no debemos rendir un culto servil al lenguaje poético tradicional." En Revista Europea, 147 (17 de diciembre de 1876), 799.

${ }^{19}$ Esa es la conclusión de Canalejas, en su discurso final, en la citada Revista Europea, 147 (24 de diciembre de 1876), 807. Si bien Revilla las reducía a dos, "que tienen evidentemente un origen germánico": "Una de estas tendencias, basada en un sentimentalismo vago y melancólico, es la representada por Gustavo Adolfo Bécquer, y la otra, que pretende cierta trascendencia filosófica, se halla bajo la dirección de Ramón Campoamor." Revista Europea, 143 (19 de noviembre de 1876), 672.

20 En la misma Revista Europea, 148 (24 de diciembre de 1876), 810. Canalejas lo había explicado ya en su Curso de Literatura general cuando afirmaba que "el poeta lírico abarca el universo en la subjetiva vida del sentimiento" (Francisco de Paula Canalejas, Curso de Literatura general, 2 vols. [Madrid: Imprenta de La Reforma, 1868-1869], II, 35. 
conflictivo con el sentido político abierto, de los nudos del corazón con el librepensamiento? En algún momento de este proceso parece haberse producido una fractura. La subjetividad lírica entendida al modo de Bécquer, su poesía "esencialmente subjetiva" según el interesante matiz de Correa-, vendría a ser, por encima de las diferencias de tono de los intervinientes, o bien egotismo incompatible con la vocación tribunicia de la mayoría o bien insulsez indigna de cualquier poeta ambicioso.

Sin embargo, la apelación al hombre histórico es engañosa, pues encubre entre los mismos liberales una visión ideologizada, esto es, superestructural y evasiva, frente a los retos reales de la "existencia histórica" en la Restauración. La intervención de Bravo y Tudela aclara, resume y fija los límites del concepto, según la opinión general:

Tomó la palabra el Sr. Bravo y Tudela, manifestando que no creía, como el Sr. Vidart, que la poesía pudiera inspirarse en la vida presente, que nada tiene de poética. En el siglo XIX no puede existir poesía sino a condición de inspirarse en ideales pasados, en sentimientos que desgraciadamente se encuentran hoy amortiguados. La prueba de esto es que la mayor parte de nuestros poetas buscan su inspiración en tiempos antiguos y los cantan. Opina, como el Sr. Vidart, que en las obras literarias, aunque la forma es muy esencial, es preferible, no obstante, el fondo. Las poesías de forma desaparecen y se olvidan, mientras aquellas que encierran un fondo bello no perecen nunca. Nuestros poetas no pueden inspirarse en este siglo, que no tiene contenido poético. Hoy no existen ideales. En una sociedad donde todo es prosa, el poeta no encuentra medios para inspirarse y crear obras bellas. ${ }^{21}$

La sorprendente idea de que el mundo contemporáneo carece de contenido poético nos desvía hacia otro aspecto no tan alejado de lo que ahora se trata: la capacidad de la lírica para reflejar e incluso juzgar la vida actual en sus aspectos menos abstractos, menos ideológicos o superestructurales. A fin de cuentas, según la definición hegeliana antes citada, la lírica es para el poeta "realización subjetiva de sí mismo" y solamente desde esa premisa le resulta legítimo contemplar o reflexionar el mundo o la sociedad. ¿Lograban recrear esa sensación de cosa vivida, interiorizada, los poemas de Campoamor o los de Núñez de Arce? O lo que es más importante: ¿acaso lo pretendían? La respuesta podría matizarse en el caso de Campoamor, pero la conclusión global parece a todas luces negativa.

${ }^{21}$ Revista Europea, 144 (26 de noviembre de 1876), 703. Otro ejemplo de esa ceguera la encontramos en la intervención de Luis Vidart, liberal como Correa, pero incapaz de asociar la concepción progresista de la poesía subjetiva a un marco contemporáneo y, lo que es más importante, intimista, personal, vivido: "Opina también, como el Sr. Revilla, que no deben cantarse ideales del pasado, pero juzga que en nuestros tiempos no existe un ideal tan preciso y bien definido como aquel. Esto engendra grandes dificultades para el poeta y explica por qué éste canta casi siempre el pasado." En Revista Europea, 143 (19 de noviembre de 1876), 672. 
Pasado un año del debate, en 1877, Manuel de la Revilla publicó la segunda edición aumentada de sus ambiciosos Principios generales de literatura. ${ }^{22}$ Merece la pena detenerse en esta obra, pues confirma, de manera más reflexiva que en el debate, el abandono, cuando no el rechazo, del modelo de Espronceda. Revilla, para empezar, asume la etiqueta de "poesía lírica o subjetiva", que vendría a ser "la expresión artística de la belleza subjetiva por medio de la palabra rítmica, o mejor la bella y artística representación de los estados de conciencia del poeta por medio de la palabra rítmica". ${ }^{23}$ Tan insulsa definición encubre, en realidad, un largo proceso discursivo de atenuación de los rasgos vistos en definiciones anteriores, en los que no me voy a detener. Bastará con este párrafo, suficientemente elocuente:

Pero entiéndase que el estado meramente subjetivo del poeta no puede bastar por sí sólo para producir el verdadero interés que exige toda composición poética. El hombre sólo se interesa por lo que es humano, por lo que él se reconoce capaz de sentir, y el estado peculiar y singularísimo de una individualidad no le interesa en lo más mínimo. Si al expresar el poeta el estado de su alma, expresa una determinación individual de algo común humano que todo hombre puede sentir a su vez; si se revela, no sólo como individuo, sino como hombre; si al leer sus obras puede cualquier semejante suyo reconocer en ellas la expresión de afectos que él ha sentido o ha podido sentir; si en ellas, bajo lo individual se oculta lo común, bajo lo transitorio lo eterno, bajo lo accidental lo permanente; si, en suma, al narrar el poeta la historia de su alma consigue exponer, sintetizándola en sí mismo, la historia de todo ser racional, su obra será mucho más interesante y conmovedora que lo sería si constituyeran su fondo las originalidades frívolas, las extravagancias, los caprichos, las anomalías de la pura subjetividad. [...] Reducir la Lírica a lo puramente subjetivo, es, por tanto, trazarle límites sobrado estrechos, y dar claras muestras de desconocer su naturaleza verdadera ${ }^{24}$

En el mismo año 1877, Rodríguez Correa volvía a prologar la segunda edición de las Obras de Bécquer. Correa no se resiste a llamar la atención sobre el hecho, aparentemente paradójico, de que la popularidad de su amigo, muerto hacía ya siete años, continuaba en crecimiento a espaldas de la obsesión didáctica, moralizadora o política de los principales representantes vivos del Parnaso lírico español:

No menos digno de llamar la atención es que el poeta haya conseguido tan rápida celebridad, sin tocar en sus fantasías ni en sus realidades nada que directamente excite el interés o las pasiones colectivas de sus contemporáneos.

Como en las de los grandes maestros, en su paleta no figuran más colores que los primordiales del iris, descompuestos en el prisma de la imaginación y del sentimiento; universales, sencillos y espontáneos, sin encenderse al contacto de pasiones políticas o de problemas sociales y religiosos (Correa 1877: VII-VIII).

${ }^{22}$ Principios generales de literatura e Historia de la literatura española (Madrid, 1877). Las referencias posteriores remiten a su edición en línea, en la Biblioteca Virtual Miguel de Cervantes, de la Universidad de Alicante. URL: http://www.cervantesvirtual.com/FichaObra.html?portal=0\&Ref=2791 (Consultado el 8 de mayo de 2009.)

${ }^{23}$ La cursiva está en el original.

${ }^{24}$ Ambas citas están tomadas de la edición digital antes citada. 
Debemos esforzarnos por captar cuánto hay de sorpresa y hasta de posible satisfacción en las palabras de Correa. Era evidente que las piezas no encajaban o, al menos, que la popularidad creciente de Bécquer revelaba el desgaste de la poesía tribunicia, o digámoslo así, oficial. Y lo que es más importante, Correa sitúa a su amigo en un plano nuevo, ajeno al debate cruzado entre liberales y conservadores, entre formalistas y contenidistas, con los intercambios evidentes entre ellos.

En realidad, el dilema no era nuevo. Ya en el momento de plena efervescencia romántica, en los años treinta, los poetas jóvenes se encontraban cercados de modo muy consciente por la disyuntiva entre hombre interior y hombre histórico. De nuevo, Espronceda parece ejemplar en este proceso. Él es quizás el único entre los españoles que supo ligar ambos planos, al darle una trascendencia moral, socialmente transgresora, a sus dilemas personales. En él, lo particular y concreto asciende con naturalidad y eficacia expresiva a aquella dimensión objetiva, o cuando menos colectiva, que le confiere la validez literaria de que hablaba Hegel: "que la intuición singular, el sentimiento y la consideración de la subjetividad en sí replegada comunica también lo más sustancial y lo más objetivo (Sachlichste) como lo suyo, como su pasión, estado de ánimo o reflexión y como producto presente de éstos". ${ }^{25}$ En el resto de los poetas románticos subsiste, por el contrario, una mala conciencia histórica que los lleva a un progresivo abandono de la expresión íntima, algo que no debe confundirse con la fácil expresión sentimentaloide, ésta sí practicada con generosidad. Parecía pretenderse de este modo, al contrario que en el modelo esproncediano o incluso en el becqueriano, que un conveniente grado de impersonalidad o de falsa objetividad sirviese para no empañar la legitimidad social y política de sus textos. Subjetivismo, sólo el necesario. Los ejemplos, tanto en el romanticismo histórico como en la época realista, son abundantísimos. El prólogo de $\mathrm{Ni}$ comedes-Pastor Díaz a las Obras poéticas de Zorrilla, ya en 1837, resume el estereotipo de una concepción conservadora que recelaba riesgos de disolución moral e incluso histórica en la expresión libre del yo, al modo de Espronceda:

Entonces el genio puede volar aún; pero vuela, como el Satanás de Milton, solitario y por el caos: el sol le causa pena; la belleza del mundo, envidia. Su poesía es solitaria como él; y como él, triste y desesperada. Canta, o más bien, llora sus infortunios, su cielo perdido, el fuego concentrado en su corazón, las luchas de su inteligencia y las contrariedades de su enigmático destino. Sus relaciones con la naturaleza no pueden ser expansivas, ni sus relaciones con los hombres simpáticas. Replegado en su individualismo, sus relaciones con Dios podrán aún ser muy vivas; pero sólo en su presencia, si la reconoce; y sólo en el universo, si tal vez ha renegado

${ }^{25}$ En la ya citada Estética, 109. 
de la Providencia: los himnos que debían consagrarse a una religión de amor, serán solamente gritos de desesperación y de impío despecho, o extravíos de un abstracto y estéril misticismo. ${ }^{26}$

La afirmación plena de la subjetividad es egoísta, en palabras de Pastor Díaz, y moralmente corrosiva. Hasta aquí, resulta coherente con la postura política del autor, en desacuerdo con la proclamada libertad de conciencia del liberalismo progresista. Podríamos decir que confirma, desde esa perspectiva, las posturas ya vistas de Alcalá o de Correa, a contrapelo de lo que ha sido y será idea fuerte del pensamiento progresista, esto es, la ligazón entre poesía subjetiva y libertad de pensamiento.

Esto último pudiera explicar la aparente paradoja de que en un primer momento sean poetas conservadores o cercanos al ámbito conservador los más extremados en la condena del "ensimismamiento" subjetivista y en la defensa de una poesía socialmente intervencionista. El realismo social del siglo XX no debe filtrar nuestra mirada atrás. Recordemos que el conservador Zorrilla, modelo de poetas futuros para Pastor Díaz, no cesaba de proclamar a gritos lo que él llamaba su "misión". Por la misma razón se explicaría el regreso ordenado de los supervivientes del romanticismo a la vía historicista y conservadora de los Schlegel, siempre en versión hispana, o el énfasis en el carácter moralizador o docente de la poesía, alejada en ellos tanto de las realidades sensibles y concretas como de cualquier conflicto de la intimidad. Sin embargo, como vamos viendo, hacia el último cuarto del siglo, los liberales parecen compartir un mismo ideal didáctico, si bien de signo opuesto, que relega de hecho la expresión más puramente subjetiva, la "esencialmente subjetiva" (Correa).

Núñez de Arce, en la polémica de 1876 que hemos seguido, no dejaba lugar a dudas, pese a haber sido conocido, sin ironía alguna, como "poeta de la duda":

Se levantó inmediatamente el Sr. Núñez de Arce, y en breves pero elocuentes y enérgicas frases manifestó que, en su sentir, no registra la historia otro siglo con más condiciones poéticas que el presente. Si es verdad que algunos géneros sufren paréntesis y eclipses, como la poesía religiosa, no es cierto que el ideal religioso haya muerto, y puede nuevamente inspirar bellos poemas. Nuestro siglo ha añadido muchas y sonoras cuerdas a la lira. Estas dudas y vacilaciones, ese sol que se hunde y ese otro que aparece, los horizontes que se abren, las grandes aspiraciones y los sueños de un porvenir venturoso no pueden menos de crear grandes poetas. La historia de este siglo nos lo confirma bien claramente. Refiriéndose después a la alusión que se le había hecho sobre el calificativo de suspirillos germánicos que había dado a cierto linaje de poesías, manifiesta que, en efecto, estas imitaciones alemanas ofrecen para él deplorables resultados. Esas composiciones breves, inocentes, verdaderos vuelos de gallina sin inspiración y sin fuego, son propias de adolescentes que se juzgan henchidos de sentimiento cuando aún no lo conocen, pero

\footnotetext{
${ }^{26}$ Nicomedes-Pastor Díaz Corbelle, Obras completas. I. Ensayos históricos, Roma sin Papa, Álbum literario (Madrid: Atlas, Biblioteca de Autores Españoles, 227, 1969), 110. Sobre la poética de Pastor Díaz puede consultarse ahora la introducción a su Poesía completa, ed. Luis Caparrós Esperante (Alicante: Universidad, 2006).
} 
no del verdadero poeta que en estos tiempos críticos debe cantar con acento viril la libertad, y, nuevo Tirteo, excitar a los ciudadanos a defender con brío y entusiasmo sus derechos. ${ }^{27}$

Parece el calco, ahora con tintas liberales, del párrafo visto antes del conservador Pastor Díaz. La inflexión en el modelo literario de los liberales progresistas de la segunda mitad del siglo no resultará tan sorprendente si tenemos en cuenta el peso ideológico que sobre ellos tendría Francisco Giner de los Ríos, fundador de la Institución Libre de Enseñanza en ese mismo año de 1876 y principal discípulo del introductor del krausismo, Julián Sanz del Río. El eticismo de Giner, su condena de Byron, su galofobia, en fin, su recuperación de los Schlegel son argumentos suficientes para explicar, al menos en parte, el cambio producido en los modelos literarios. ${ }^{28} \mathrm{Y}$ no sólo en ellos, aunque eso nos llevaría demasiado lejos. Fuese como fuese, las consecuencias de esta toma de partido no podían ser más nefastas para la lírica española, pues cualquiera de esas soluciones los alejaba del camino real que tomaría o estaba tomando ya la lírica contemporánea.

Las desgastadas herramientas discursivas de los participantes en la discusión de 1876 - Correa y Valera con matices- les impiden dejar constancia de la paulatina aparición de una nueva modalidad, cercana a la poesía subjetiva, para la que aún no disponen de nombre. Esa nueva modalidad, diferente del romanticismo, aunque con indudables contactos con él, apunta ya a valores simbolistas, como la sugerencia, y reniega del didactismo a favor de las sensaciones y la brevedad. A fin de cuentas $-\mathrm{y}$ damos con un hecho capital de la modernidad literaria-, Bécquer, como Baudelaire en Francia, representa la recuperación de rasgos del viejo romanticismo para transformarlos en una nueva sensibilidad lírica. Se trataría, a fin de cuentas, de una nueva poesía que ya no es por más que los tertulianos no pudieran saberlo-ni clásica, ni romántica, ni realista.

Aunque fuese de modo difuso, aunque faltasen categorías para definirla, la nueva sensibilidad se entreveía. Juan Valera, con su peculiar estilo, intentaba acotarla mediante la defensa de la forma y de la belleza como absolutos. No en vano, él sabrá valorar la profunda novedad de $A z u l$, de Rubén Darío, años más tarde. Ya en la discusión de 1876 había hecho unas afirmaciones que, con toda probabilidad, hubieron de parecerle a sus contertulios una más de sus extravagancias intelectuales, cosas de don Juan:

\footnotetext{
${ }^{27}$ Revista Europea, 144 (26 de noviembre de 1876), 704.

${ }^{28}$ Es esclarecedor el artículo de Joan Oleza, "Calderón y los liberales", en Giornate calderoniane. Calderón 2000. Tai del Convengo Internazionale Palermo. 14-17 Dicembre 2000, ed. Enrica Cancelliere (Palermo: Flaccovio Editore, 2003), 395-418.
} 
Dijo después el Sr. Valera que la poesía no era en absoluto más que belleza, forma, sin trascendencia y sin que reporte enseñanza ninguna. [...] Dice Carlyle que sólo debe cantarse aquello que no se puede decir; y esto, a mi juicio, es una completa teoría del arte. Tómese una poesía de Bécquer, y desde luego parece que todo aquello se le podría ocurrir a cualquiera. Sin embargo, está de tal modo presentado, que hiere vivamente nuestra fantasía y conmueve nuestro corazón. $^{29}$

La etiqueta de "poesía subjetiva", en este contexto, resulta insuficiente para definir los nuevos aires líricos. Si parece evidente la consecución para ella de un prestigio más que dudoso en años precedentes, lo logra al precio de la devaluación de su sentido original. Buena prueba de ello lo tenemos en el hecho de que incluso Campoamor, por sorprendente que resulte, no dudaba en considerarse a esas alturas del siglo un poeta subjetivo. Era todo un indicio del valor adquirido por la etiqueta. Así lo afirmaba en un trabajo titulado "La originalidad y el plagio. (Carta al Sr. Fernández Bremón)”, fechado en diciembre del año anterior, 1875: "La teoría de la originalidad absoluta es un callejón sin salida del arte. Los poetas más subjetivos, más originales, somos (juro a las personas modestas que digo somos afectando un orgullo que no tengo) los menos dignos de ser imitados". ${ }^{30}$

Pero Campoamor, siempre celoso de su originalidad, era también consciente de los derechos adquiridos por Bécquer, años después de su oscura muerte, para disfrutar casi en exclusiva de ese timbre de originalidad y subjetividad. Por tanto, la "poesía subjetiva" de Bécquer habría de ser otra cosa, algo diferente de lo que afirma ser él mismo.

Los límites del peculiar subjetivismo de Campoamor -y de su visión de futurohabrían de aclararse en la segunda edición de su Poética (1890). Allí, aunque fuese sólo para defender su territorio recién conquistado, esboza una nueva categoría a la que arrojar la incómoda posteridad de Bécquer: el "género sugestivo". La novedad terminológica, al menos en el marco español, es un acierto, por más que tenga un matiz despectivo en su pluma. Hay una sustancial diferencia, escribirá, entre poesía subjetiva y lo que él denomina "género sugestivo", que sería radicalmente antimoderno:

No quiero dejar de condenar un cierto pseudotrascendentalismo patológico que han inventado algunos imitadores de Heine, y que consiste en un subjetivismo sin objeto, en un histerismo soñador que crea un género nervioso, asexual, amorfo y que muchos llaman sugestivo y que no sugiere nada. [...] En estos rompecabezas no es tan interesante lo que se dice como lo que se calla, y en ellos la solución siempre se deja a cargo del curioso lector, sobre todo si es aficionado a descifrar charadas. ${ }^{31}$

${ }^{29}$ Revista Europea, 147 (17 de diciembre de 1876), 799.

${ }^{30}$ Ramón de Campoamor, Obras completas de Don Ramón de Campoamor. III. Polémicas filosóficas y literarias (Madrid: González Rojas, 1901), 202.

${ }^{31}$ Recogido en el volumen anterior: 310. 
Don Ramón, al confundir sugerencia con charadas, choca frontalmente con el rasgo caracterizador y más rico de la poesía en alza, aquel que supondrá el renacimiento de la lírica hispánica del final de siglo y del siguiente. La sugerencia, la expresión indirecta, la que permite arrancar de las palabras más de lo que literalmente expresan, el "no es tan interesante lo que se dice como lo que se calla", era la gran conquista del nuevo subjetivismo de Bécquer y, desde luego, su rasgo más moderno. Se trata, como el propio poeta señala en la reseña de La soledad, de Ferrán, de una dimensión nueva de la poesía subjetiva:

Hay otra [poesía] natural, breve, seca, que brota del alma como una chispa eléctrica, que hiere el sentimiento con una palabra y huye, y desnuda de artificio, desembarazada dentro de una forma libre, despierta, con una que las toca, las mil ideas que duermen en el océano sin fondo de la fantasía. ${ }^{32}$

La incipiente vía "sugestiva", parafraseando a Campoamor, es decir, el desarrollo breve, abierto y sensorial del poema, significaba para los poetas "oficiales" una vuelta de tuerca en el ensimismamiento subjetivista que condenan. ${ }^{33}$ Y lo que sería incluso peor, desde la inflexible perspectiva didáctica que defienden, los valores modernos de la sugerencia se confunden ni más ni menos que con charadas gratuitas. Dicho de otro modo, la claridad es para ellos antes un imperativo moral que estético. Hace falta ser absolutamente claro, tanto en la forma como en la literalidad de las propuestas. El lenguaje heredado no se cuestiona y, de este modo, tampoco resulta válido romper su cáscara retórica en busca de otras verdades, de otros discursos, de su matriz irracional. En consecuencia, ni Góngora -tan sensorial, por otra parte- ni Bécquer o Rosalía de Castro tienen fácil acomodo en esa poética. Si la estirpe de la poesía becqueriana resultaba para Núñez de Arce, como hemos visto, “composiciones breves, inocentes, verdaderos vuelos de gallina sin inspiración y sin fuego", ya no digamos qué opinión habrían merecido los poetas franceses que apuntaban en el horizonte. Por no hablar de Rubén.

32 Gustavo Adolfo Bécquer, en la citada edición electrónica del Instituto Cervantes http://cvc.cervantes.es/obref/rimas/apendices/resena01.htm

\footnotetext{
${ }^{33}$ Lo había señalado claramente Vidart, en el debate de 1876, Revista europea, 143 (19 de noviembre de 1876), 672: "Respecto a la tendencia didáctica que manifiesta hoy nuestra poesía lírica, en contraposición con el excesivo romanticismo que se advierte en el teatro, cree que se debe a la diferencia de públicos. El del teatro, más apasionado que juicioso, quiere y exige cosas imposibles, acciones extraordinarias que le conmuevan hondamente, mientras que el público que lee, más restringido, y por lo común más selecto o ilustrado, gusta de cosas que se expliquen claramente y sin dificultad. Por esto, cree el orador que es más aceptable la tendencia didáctica de nuestros tiempos que la opuesta tendencia de exagerar la importancia de la forma, porque, caso de conceder más importancia a alguno de los elementos de la poesía, debe ser al fondo."
} 
Bien es cierto, podemos concluir, que la modernidad literaria en Francia anunciaba por aquellos años finales de siglo la disolución del sujeto lírico, que ejemplificarán Rimbaud o Mallarmé. Esa disolución, sin embargo, presuponía su existencia previa, su fortaleza previa, algo que en el caso español rondaba de modo fantasmagórico por interminables y estériles debates como los que hemos analizado. Al finalizar el siglo, y una vez más, el tren parecía pasar de largo ante sus narices. Afortunadamente, también hubo poetas que entendieron en su práctica creativa esa dimensión necesaria de lo más inmediato, concreto, íntimo y conflictivo. Alguno, como Pastor Díaz, renegó muy pronto, asustado de las consecuencias. Algún otro, como Espronceda, alcanzó la difícil síntesis de El diablo mundo, aun tan mal leído. Bécquer, por repetido que resulte, sentó las bases del simbolismo español sobre esa vía negada por tirios y troyanos. Los poetas futuros, desde Rubén Darío a Juan Ramón Jiménez, sabrían reconocer la deuda.

\section{Luis Caparrós Esperante Universidade da Coruña}

